\title{
Review Article \\ Oral Complications and Management Strategies for Patients Undergoing Cancer Therapy
}

\author{
Hai Ming Wong ${ }^{1,2}$ \\ ${ }^{1}$ Faculty of Dentistry, The University of Hong Kong, Hong Kong \\ ${ }^{2}$ The Prince Philip Dental Hospital, 34 Hospital Road, Hong Kong \\ Correspondence should be addressed to Hai Ming Wong; wonghmg@hku.hk
}

Received 4 September 2013; Accepted 19 December 2013; Published 8 January 2014

Academic Editors: T. Castroflorio and S. R. Fidel

Copyright (C) 2014 Hai Ming Wong. This is an open access article distributed under the Creative Commons Attribution License, which permits unrestricted use, distribution, and reproduction in any medium, provided the original work is properly cited.

\begin{abstract}
With cancer survival rate climbing up over the past three decades, quality of life for cancer patients has become an issue of major concern. Oral health plays an important part in one's overall quality of life. However, oral health status can be severely hampered by side effects of cancer therapies including surgery, chemotherapy, radiotherapy, and hematopoietic stem cell transplantation. Moreover, prevention and treatment of these complications are often overlooked in clinical practice. The present paper aims at drawing health care professionals' attention to oral complications associated with cancer therapy by giving a comprehensive review. Brief comments on contemporary cancer therapies will be given first, followed by detailed description of oral complications associated with cancer therapy. Finally, a summary of preventive strategies and treatment options for common oral complications including oral mucositis, oral infections, xerostomia, and dysgeusia will be given.
\end{abstract}

\section{Introduction}

Cancer, from its initial diagnosis to the completion of its treatment, is a heart-rending experience for many. It is a period of great pressure and stress for not only the patients themselves but also their families and friends. According to the United States Cancer Statistics 2009, the National Program of Cancer Registries, the ten ranking cancers by site in the American population (per 100,000 persons) are prostate (137.7), breast (123.1), lung and bronchus (64.3), colon and rectum (42.5), corpus and uterus, NOS (25.1), urinary bladder (20.5), melanomas of the skin (19.4), non-Hodgkin's lymphoma (18.9), kidney and renal pelvis (15.7), and thyroid (13.2) [1]. The American Cancer Society has estimated that there will be approximately 1,660,290 new cancer cases being diagnosed in 2013. As the second leading cause of death in the United States, preceded only by heart disease, cancer is expected to take the lives of 580,350 Americans in the year of 2013, that is, about 1600 deaths per day $[2,3]$. Though the survival statistics can vary significantly with the stage at which the cancer is diagnosed as well as the cancer type itself, survival rates continued to climb over the past years. In fact, the 5year relative survival rate for all cancers diagnosed from 2002 to 2008 is $68 \%$, compared to $49 \%$ in 1975-1977 [3]. Coupled with the ongoing advances in cancer detection and treatment modalities, the future trend would entail increased likelihood for dentists to encounter patients who are currently, or have previously been, under cancer therapy.

Contemporary cancer treatment modalities commonly include surgical resection, chemotherapy, radiotherapy, and hematopoietic stem cell transplantation (HSCT), a form of immunotherapy, either administered alone or used in combination. Although the effectiveness of cancer treatment has continued to improve over the past decades, collateral damage to the head and neck structures is frequently encountered as an unwanted consequence. Radio- and chemotherapy can cause direct harm to the soft and hard tissue of the oral structures, whereas their systemic toxicity can give rise to indirect damages. These oral complications, be they acute or chronic, may arise throughout and after cancer treatment and often encompass mucositis, dysgeusia, and infectious diseases [4]. Although literature has shown that the oral health status in most cancer patients mirrors those of the general 
population, poorly restored dentition, moderate to advanced periodontal disease, and other pathologies associated with negligence of oral health care, the many oral complications as sequelae of aggressive cancer treatment can greatly hamper patients' quality of life; this necessitates optimal oral health care [5]. Maintaining oral health is essential in the preservation of daily functions, such as eating, verbal and nonverbal communications, and the prevention of infectious diseases.

While the necessity of dental clearance is debatable and empirical guidelines vary from center to center, assessment, treatment, and prevention of any preexisting pathological condition make up an important aspect of the overall treatment outcome in cancer patients $[6,7]$. Unfortunately, priority is often given to the more "life-threatening" condition that is cancer, and administering oral care has become an activity frequently neglected $[8,9]$. Yet, it is the ethical and medical/legal responsibility of all health care practitioners, including professionals in the field of dentistry, to ensure that the oral health status of patients undergoing cancer therapy is thoroughly evaluated. Thus, it is the aim of this paper to paint a detailed picture for dental professionals on the topic of oncology related oral care. Cancer treatment modalities will be introduced first and oral complications of cancer therapy will be discussed. Some therapeutic alternatives that may help to alleviate the painful and debilitating adverse effects will also be presented.

\section{Management of Malignancy}

Treatment of malignancy is complex and often involves a multidisciplinary approach. It is beyond the scope of this paper to give an in-depth review of different types of cancer therapy. Brief comments on cancer treatment modalities, including surgery, chemotherapy, radiotherapy, and HSCT, will be made to give a general picture of contemporary mainstream cancer therapies.

Surgery has come a long way in the treatment of malignancy and is still one of the most common methods in managing primary solid tumors today [10]. In dentistry, the impacts of surgical resection on patients' lives are particularly evident in the cases of oral and oropharyngeal cancers. Over the past decades, advances in surgery have resulted in major changes in surgical approaches to the mandibular areas and cervical lymph nodes [11]. In addition, safer anesthesia, tumor ablation via radiofrequency, and radiosurgery have opened up many more options and alternatives for the professionals in the effective management of the disease [12]. Combined with advances in various reconstruction techniques, the functional and aesthetic outcomes have been greatly improved in cancer patients. Nowadays, survivors of head and neck cancers no longer have to live with severe functional disabilities or aesthetic impairments that compromise their quality of life [11].

Chemotherapeutic agents are drugs designed to have a selective toxicity towards the tumor cells. Current chemotherapeutic agents are often cytostatic or cytotoxic in nature to prevent the rapid division of the malignant cells and/or destroy them in the process [13]. Unlike surgery and radiation therapy, whose usages are limited to cancers confined to specific areas of the body, the major advantage offered by chemotherapy is the ability to target widespread or metastatic cancer [14]. Yet, even the most modern chemotherapeutic agents are not without their shortcomings. Ironically, while exploiting the tumor cells' characteristic feature of shortened cell cycle and having a selective toxicity design in mind, these anticancer agents are not so "specific" as they also act upon normal cells with a high turnover rate (accelerated cell cycle) such as bone marrow cells, hair follicle cells, and the epithelial cells of the gastrointestinal tract $[13,15]$. Some common drugs used in chemotherapy for oral cancer include 5-fluorouracil, bleomycin, cisplatin, cyclophosphamide, methotrexate, and vinblastine [16].

As one of the most effective forms of cancer treatment, radiation therapy plays an indispensable role in the management of many head and neck cancers as well as lymphomas. The dose of ionizing radiation administered often depends on factors such as the location of the malignancy, the type of the malignancy, the sensitivity of the surrounding normal tissues, and whether radiation is used as the sole treatment option [17, 18]. Typically, for most head and neck cancer patients, a dose of 2 Gy per fraction is delivered once a day, five days per week, over a five-to-seven-week period with a total dosage of 64-70 Gy [19]. The amount of radiation used to treat malignant lymphomas is usually lower [17]. Although the main aim of radiotherapy is to deliver a concentrated and lethal dose of radiation to the solid tumor while at the same time minimizing the exposure of the surrounding tissues, the salivary glands, oral mucosa, and jaws are inevitably covered in the blast radius, resulting in a variety of problems within the area [20].

HSCT, also known as bone marrow transplant, has formed an important part of the treatment modalities for many malignant diseases, acute and chronic leukemia, myelodysplastic syndromes, myeloproliferative disorders, multiple myeloma, and non-Hodgkin's lymphomas, as well as a number of other nonmalignant diseases such as aplastic anemia $[21,22]$. For patients to undergo the HSCT procedure, they are required to partake in preoperative conditioning which often involves the use of cyclophosphamide and total body irradiation (TBI). The objective is to eradicate the cancer and induce an immunosuppressive environment that permits engraftments. Although HSCT can result in more cures and remissions compared to alternative treatment, it also tends to cause greater morbidity and mortality with the mortality rates of less than $2 \%$ and $10 \%$ for some autologous and allogeneic transplantations, respectively. With as much as $40 \%$ of the advanced cancer patients dying from complications related to transplantation, further research is warranted to determine the best ablative regimens for specific conditions and reduce the toxicity of the preparative regimens [21].

\section{Oral Complications of Cancer Therapy}

3.1. General Considerations and Overview. Despite the encouraging evolvement in cancer management over the past decades, one should bear in mind that current treatment modalities do have the potential to result in debilitating and sometimes life-threatening adverse effects that not only 


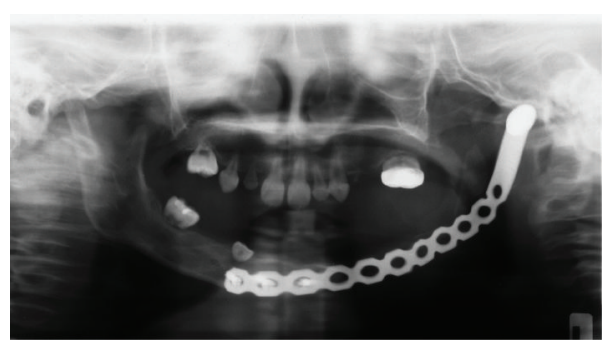

(a)

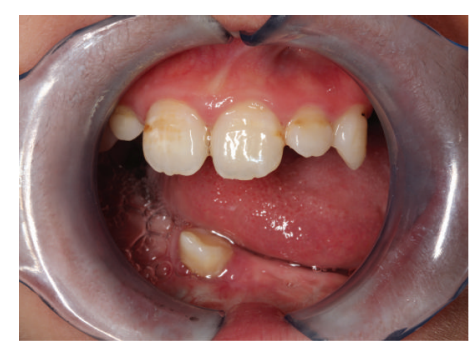

(b)

FIGURE 1: (a) Surgical resection involving part of the mandible in a patient with rhabdomyosarcoma. (b) Limited mouth opening after surgical resection.

decrease the patients' quality of life but also increase their morbidity and mortality.

Oral complications associated with cancer therapy encompass diseases such as stomatitis, infection, bleeding, mucositis, pain, loss of function, and xerostomia [23]. The mucosa, the periodontium, and the teeth are the three anatomical sites most commonly associated with these complications [24]. Oral complications associated with specific oncological therapy will be discussed in the following sections.

3.2. Complications Associated with Surgery. The long-term complications associated with the surgical treatment of oral cancers are many; they range from functional limitations on speech, mastication and swallowing, damages to the cranial nerves and the resultant neurological problems, chronic fistulas, and healing issues to aesthetic considerations such as severe disfigurement and prosthetic rehabilitation; taking these functional and aesthetic impairments, together with their psychological implications, the patients' long-term quality of life could be hampered [25].

Surgical resection of cancers in the oral cavity can negatively impact speech, mastication, and swallowing in a very significant way. In general, surgical ablation that involves the most anterior region of the tongue is often associated with significant speech alteration, whereas ablation that incorporates the posterior tongue affects swallowing [26-29]. With tumor ablation and the subsequent loss of a significant portion of the tongue, the manipulation and formation of the bolus (the oral preparatory phase) and the transfer of bolus from the anterior oral cavity to the posterior tonsillar area (the initiation of the swallowing reflex) are severely restricted [30]. The situation could be further complicated where surgical management also involves the floor of mouth, maxilla, and mandible with the adjacent tissues (Figure 1(a)); those are vital structures for mastication. Resection of the maxilla or the mandible could prove problematic for the patient during grinding as the stable and reproducible stomatognathic system relationships or tooth-to-tooth contact is lost, resulting in diminished biting force $[30,31]$. Furthermore, combined with soft tissue bulk and sensation loss, the ability of the patient to manipulate food bolus to and fro from occlusal table and its consolidation before deglutition are impaired. Thus, the overall masticatory efficiency, which encompasses manipulation, trituration, and consolidation, being the result of synchronous interaction of both hard and soft tissues, is drastically reduced [32].

Trismus, that is, limited mouth opening, is a common complaint after oral cancer surgery (Figure 1(b)). Postoperative healing, including fibrosis and scar contraction, often results in restricted interocclusal opening of less than $35 \mathrm{~mm}$ between the maxillary and mandibular incisors. Procedures that may lead to trismus commonly include maxillary surgery involving the origin of medial and lateral pterygoid muscles from the pterygoid plates and mandibulectomy involving any of the muscles of mastication (the temporalis insertion to the coronoid process, the masseter insertion to the angle and ramus, and the pterygoid insertions to the medial ramus and condylar neck) [30]. Note that trismus could be exacerbated by the fibrotic changes due to combination radiotherapy.

Additionally, the resection of primary tumor and lymph nodes has put several cranial nerves at risk: spinal accessory nerve, phrenic nerve, hypoglossal nerve, lingual nerve, vagus nerve, sympathetic trunk, and marginal mandibular branch of the facial nerve. The size of the tumor and its location and the extent of the neck pathology often require the nerves involved or in close association to be sacrificed. The issue with access and certainty of satisfactory tumor removal can compromise the integrity of the cranial nerves within the area [30].

Fistula is another complication often associated with oral oncologic surgeries. The risk of fistulas being developed often depends on the general physical and nutritional status of the patient, the incision design, and the tumor type and stage. Its management is particularly difficult where radiation therapy is also involved, as surgical wound closure is delayed due to low oxygen tensions, vasculitis, endothelial fibrosis, and reduced blood supply [25]. Fistulas generally occur 3-4 weeks after surgery, but they can also develop as early as 1 week. Persistent or chronic fistulas are those that remain present 1 month after the surgery. In addition, patients may present with low grade fever, inflammation, and induration of the skin flap under the area of dependant drainage. Prevention is often the best treatment, but surgical excision and closure of the mucosa and skin are indicated where the problem persists $[25,33]$.

The complex anatomy of the bone and associated muscle attachments often require careful planning and placement of plates and screws to stabilize bone segments and secure 
bone flaps in mandibular osteotomies and/or resection. Any abusing of the reconstruction principles and overmanipulation of the material, along with unbalanced masticatory force, can result in hardware failure ranging from fracturing of the plates, loosening of the screws, and mobility of the mandibular segments to exposure of the material through the overlying soft tissue and secondary infection [25]. Although early treatment of the problem is preferred, surgical intervention may be delayed due to adjunctive radiation therapy which can compromise the wound healing; in which case, hyperbaric oxygen treatments may improve the healing abilities of the soft tissue overlying the hardware replacement [33-35].

Appropriate prosthetic and functional rehabilitation, which entails the reestablishment of a functional maxillomandibular complex providing for an adequate dentition for mastication with underlying bone support for facial features and soft tissue for the restoration of speech and swallowing, served as the desired endpoint for many patients. However, such a feat may not always be feasible as many factors play into this prosthetic problem. As noted by Kolokythas, the issue is a multidisciplinary one; it may not always be possible to convene all members of the treatment team to discuss the treatment plan of the oral cancer patient prior to resection. Thus, the plans for reconstruction may often have to be formed postoperatively and may not be ideal. Furthermore, the extent of the resection, several postsurgical and radiation associated complications, may not allow for the ideal rehabilitation. The patient's compliance and financial background may also be a barrier to reaching the final restorative goal [25].

\subsection{Complications Associated with Chemotherapy. Chemo-} therapeutic agents have gained a notorious reputation in damaging not only the malignant cells but also the normal tissue in the patient's body. The level and the type of toxicity of the treatment greatly depend on the overall immune status of the patient prior to and during chemotherapy, the regimen itself, the frequency and the dosage of the treatment, the route of administration, and the type of tumor. In many patients, these drugs can cause a number of oral complications including mucositis, pain, infection, hemorrhage, xerostomia, and neurologic and nutritional problems [14].

Oral mucositis $(\mathrm{OM})$ is an iatrogenic condition of erythematous inflammatory changes which tends to occur on buccal and labial surfaces, the ventral surface of the tongue, the floor of the mouth, and the soft palate of patients receiving chemotherapy [36]. Its severity ranges from localized (Figure 2) to generalized erythema (Figure 3) to frank ulceration and hemorrhage [37]. The initial condition is often described as a burning or tingling sensation making the mouth hypersensitive to foods. And as the condition progresses, eating, swallowing, and talking become increasingly difficult [38]. In the more severe cases, OM can compromise the airway leading to anoxia-induced brain injury and even death [39-41]. As a form of iatrogenic stomatitis, mucositis usually starts off with aplasia 7-14 days after the initiation of chemotherapy. Clinically, the earliest sign may be characterized by leukoedema, appearing as a diffuse, poorly

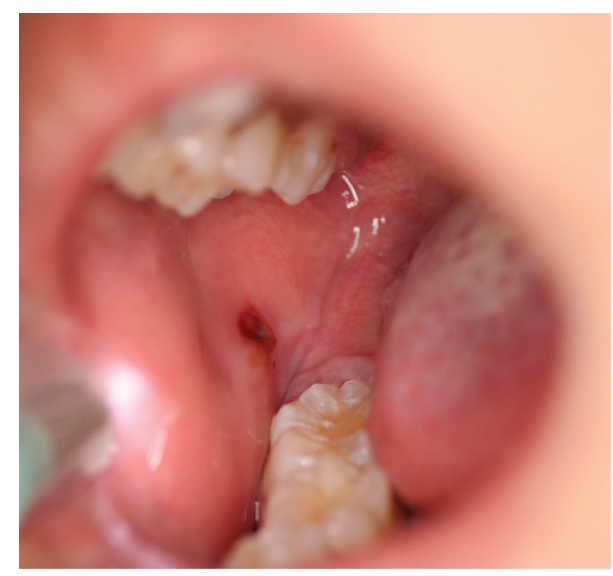

FIGURE 2: Localized buccal mucositis in a patient with osteosarcoma.

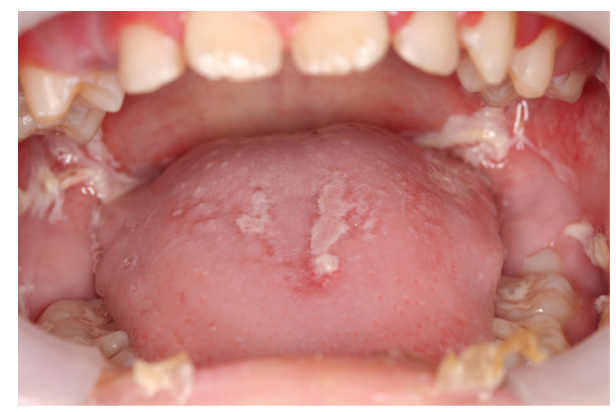

FIgURE 3: Generalized mucositis in a patient with acute myeloid leukemia.

defined area of milky-white opalescence most noticeable on the buccal mucosa, which will disappear upon stretching [14]. In the following 1-2 weeks, a loss of epithelial structure and integrity is observed, and severe ulceration develops [42]. In general, $\mathrm{OM}$ can be assessed both clinically and with subjective input from the patient. The World Health Organization (WHO) has also provided a useful grading scale that combines both objective and subjective elements (Table 1) [43]. Current literature's reported incidence of OM is highly variable, ranging from $75 \%$ to $99 \%[44,45]$. The current working biophysical model of OM as proposed by Sonis [40] involves 5 phases: initiation, upregulation and message generation, amplification and signaling, ulceration, and healing. Initiation involves direct irreversible and reversible DNA damages and the generation of reactive oxygen species via the chemotherapeutic agents. In the upregulation and message generation phase, transcription factors (e.g., NF- $\kappa \mathrm{B}$ ) are activated, resulting in the production of messaging and effector proteins including the proinflammatory cytokines and enzymes. Positive feedback loops in phase III increase cytokine production and thus signal amplification; apoptosis and tissue injury ensue. In the ulcerative stage, clinically evident erosions are detected; bacterial colonization and additional proinflammatory cytokine secretions are also involved. In due course, spontaneous healing occurs where epithelial cells migrate to cover the ulcerations [40]. Several 
TABLE 1: WHO oral mucositis scale [43].

\begin{tabular}{ll}
\hline Grade & Clinical presentation \\
\hline 0 & Normal \\
1 & Soreness with/without erythema \\
2 & Ulceration and erythema \\
3 & Ulceration and extensive erythema, patient cannot \\
4 & swallow solid food \\
\hline
\end{tabular}

chemotherapy agents have been associated with OM $[46,47]$. A summary of these drugs is given in Table 2.

Chemotherapy-related oral infections, which account for $25-50 \%$ of the total infections, contribute significantly to the morbidity and mortality in these patients [48]. Susceptible areas include teeth, gingiva, salivary glands, and mucosa. It should be noted that in the myelosuppressed patient the cardinal signs of infection such as erythema and swelling are not always present. Therefore, the more reliable indicators such as fever, pain, and the appearance of lesions should be used to closely monitor all suspected infections [14]. Common oral flora and opportunistic microorganisms include coagulase-negative Staphylococci and Streptococci, Klebsiella pneumonia, Pseudomonas aeruginosa, and Escherichia coli [48-51]. It has been shown that pathogenic microorganisms found subgingivally or in periradicular area may cause acute exacerbations of preexisting periodontal or periradicular infections when the granulocyte count dips below $1000 / \mathrm{mm}^{3}$ $[49,52]$.

Perhaps, the most dangerous complication in the realm of infections comes from fungal species, most notably Candida species $[48,49]$. The mortality rate from systemic fungal infections is much higher compared to other infections, with the majority believed to have originated from the oral cavity [49]. Clinically, fungal infections in the oral cavity can manifest in several forms, with erythematous or pseudomembranous candidiasis being the most common. Erythematous candidiasis presents itself as patchy or diffuse areas of erythema, often occurring on the palate. Pseudomembranous candidiasis appears as curd-like or patchy white lesions, which can be rubbed off but will produce bleeding and erosion in the tissue underneath. Also worth mentioning is hyperplastic candidiasis, which resembles leukoplakia as elevated white plaques that cannot be wiped off $[53,54]$. Particularly troublesome is the chronic atrophic candidiasis, which is often accompanied by angular cheilitis and denture stomatitis. Angular cheilitis, an infection at the corner of the mouth, may sometimes involve Staphylococcus species. Illfitting denture bases, usually of the maxilla, can be a source of chronic irritation and a reservoir for Candida albicans [14].

Viral infections frequently seen in patients undergoing chemotherapy include the herpes simplex virus (HSV), varicella zoster virus (VZV), and cytomegalovirus (CMV) [14]. Viral reactivity is not uncommon during periods of myeloimmunosuppression, particularly with HSV infections. With incidence of recurrent infection reported up to $48 \%$, HSV infected patients often report severe, painful, and prolonged ulcerations atypical of those discovered in immunocompetent hosts [55-57]. HSV recurrence typically appears 7-14 days after chemotherapy, and lesions can often be seen on lips and keratinized mucosa as small cluster of vesicles that rapidly ulcerate and coalesce $[55,58]$. Fortunately, it is selflimiting and resolves in 2 weeks. VZV infections, also known as herpes zoster/shingles, can occur within the trigeminal dermatome. Lesions can be seen on the face or intraorally with the characteristic feature of halting abruptly at the midline on the side of the respective trigeminal divisions involved. Similar to HSV, VSV recurrence is confined to keratinized mucosa and is shown to manifest several weeks after the completion of chemotherapy, with widespread, painful lesions lasting up to several weeks. Intraorally, CMV infections may be seen as irregular pseudomembranous ulcerations, coupled with common clinical manifestations such as esophagitis, gastritis, colitis, hepatitis, pneumonia, and retinitis. Furthermore, a fever may also be involved but often resolves in 3-5 days. Dissemination of CMV in immunosuppressed patients is often fatal [14].

Intraoral bleeding is another complication associated with chemotherapy. The bleeding can be spontaneous, traumatically induced, or effect from existing pathology [59, 60]. It can also be the result of thrombocytopenia secondary to hematopoietic tissues suppression. Laboratory tests should be used to assess bleeding potential. Thrombocyte count and bleeding time can give the dentist a decent picture of the quantity, quality, and function of platelets.

\subsection{Complications Associated with Radiotherapy. Orofacial} tissues that may be influenced by head and neck radiotherapy include salivary glands, taste buds, mucous membranes, bone and teeth, the temporomandibular joint (TMJ), and related musculatures. In general, complications from radiation therapy are categorized into acute and chronic/late types. The acute effects usually develop early in the radiation treatment period and persist 2-3 weeks after completion of treatment, whereas the late effects may become evident at any time after treatment completion, ranging from weeks to years [61]. In fact, it is shown that in $90 \%$ to $100 \%$ of the patients whose radiation therapy covers the oral cavity some degree of oral complication will always develop [62].

Xerostomia is perhaps the most commonly reported oral sequela among patients receiving radiotherapy for head and neck cancers. The effects of radiation on salivary glands have been well documented. Ionizing radiation may cause irreversible damage to glandular tissue and loss of salivary fluid secretion; the gross architecture of the gland is slowly replaced by ductal remnants and fibrous tissues with lymphocytes and plasma cells infiltration [63, 64]. The progressive glandular atrophy and fibrosis and the reduction in salivary outflow occur shortly after the initial exposure to radiation and intensify thereafter [65]. Mantle, unilateral, and bilateral fields of radiation are associated with a reduction of salivary flow by $30 \%$ to $40 \%, 50 \%$ to $60 \%$, and $80 \%$, respectively. For patients whose major salivary glands are in the radiation fields, the prevalence of xerostomia is shown to range from $94 \%$ to $100 \%$ [66-68]. Clinically, the condition becomes 
TABLE 2: A summary of mucosatoxic chemotherapy agents (data adapted from Köstler et al., 2001 [46], and Saadeh, 2005 [47]).

\begin{tabular}{ll}
\hline Category & Drugs \\
\hline Alkylating agents & $\begin{array}{l}\text { Busulfan, carmustine, chlorambucil, cisplatin, cyclophosphamide, dacarbazine, estramustine, ifosfamide, } \\
\text { lomustine, mechlorethamine, melphalan, oxaliplatin, procarbazine, and thiotepa }\end{array}$ \\
Anthracyclines & $\begin{array}{l}\text { Daunorubicin, doxorubicin, epirubicin, idarubicin, and mitoxantrone } \\
\text { Capecitabine, cytarabine, floxuridine, 5-fluorouracil, hydroxyurea, 6-mercaptopurine, methotrexate, } \\
\text { pemetrexed, and 6-thioguanine }\end{array}$ \\
Antimetabolites & Actinomycin d, amsacrine, bleomycin, mithramycin, mitomycin, and plicamycin \\
Natural products & Etoposide, irinotecan, and streptozotocin \\
Taxanes & Docetaxel and paclitaxel \\
Vinca alkaloids & Vinblastine, vincristine, vindesine, and vinorelbine \\
Others & Carboplatin, fludarabine, gemcitabine, interferons, interleukin-2, mitotane, and topotecan \\
\hline
\end{tabular}

apparent as saliva becomes "scant, sticky, and viscous." The patient may experience oral discomfort and pain. Furthermore, dryness of the mucosa may put the patient at risk of oral infections and can lead to difficulties in speech, chewing, and swallowing, which significantly affects their quality of life $[69,70]$. Reduced salivary outflow can also increase the susceptibility to dental caries and compromise the mucosal integrity [7]. It has been shown that xerostomia is associated with as little as two or three doses of $2 \mathrm{~Gy}$ each, whereas doses greater than $30 \mathrm{~Gy}$ can usually result in permanent or semipermanent xerostomia [71, 72]. It is interesting to note that a "compensatory" hypertrophy of the unirradiated salivary gland may occur after a few months and up to 1 year after therapy which may alleviate the condition; yet, if all the major salivary glands are included in the field of radiation, salivary function is expected to fall as much as $50-60 \%$ within the first week $[73,74]$. Thus, it is suggested that, if irradiation of salivary tissues can be spared by patient positioning or shielding, the resultant salivary gland dysfunction may be reduced [75].

As taste is associated with salivary functions, it is not uncommon to hear complaints of taste loss in relation to xerostomia as a result of head and neck radiotherapy. Dysgeusia can occur at a rapid rate and be exacerbated at up to an accumulated dose of $30 \mathrm{~Gy}$, then the progress of taste deterioration would slow down as perception for all four tastes, that is, salty, sweet, sour, and bitter, approaches zero [75]. In addition, microvilli damages brought about by the radiation may cause secondary taste loss [75]. Fortunately, the condition seems to be reversible. In the majority of the cases, taste acuity is reported to be partially restored and fully restored 20-60 days and 2-4 months after radiation therapy, respectively [76]. However, there were reports of subjective residual hypogeusia [75].

Perhaps, the most alarming and worrisome acute reaction for patients receiving radiotherapy is the radiation-induced mucositis. The high turnover rate and low radiation resistance of the mucosal cells within the oral cavity, pharynx, and larynx make them susceptible to destruction from head and neck fractionated external beam irradiation. In fact, the literature shows that mucosal erythema could develop within 1 week of fractionated doses of, each, 2 Gy per day [77]. The condition will intensify with continued treatment by daily regimen doses of greater than $2 \mathrm{~Gy}$ and large treatment volumes such that almost all patients would develop confluent mucositis by the third week [77]. Initially, the erythema is the result of epithelium thinning and vascular dilation, inflammation, and oedema of the submucosa [78]. As the therapy continues, however, the mucosa will become denuded, ulcerated, and covered with a fibrinous exudate [78]. There may also be bleeding. The patient is often accompanied by symptoms of intense pain, dysphagia, and odynophagia, which, in many cases, prevent oral intake and necessitate the use of parenteral analgesics; as a result, not only the patients' quality of life but also the implementation of the therapy itself is greatly affected [79]. Radiation-induced mucositis usually persists 2-3 weeks after completion of radiotherapy $[77,80]$. About $90 \%$ to $95 \%$ of the patients would show complete resolution by the 4 th week [77].

It is now widely accepted that, through the generation of free radicals, ionizing radiation can cause alteration of the vascular elements in the bone within the irradiated fields. Overtime, the irradiated area will show endothelial cell death, hyalinization, thrombosis, and obliteration of vessels; consequently, the periosteum and marrow spaces will become fibrotic while the osteoblasts and osteocytes will necrose [75]. The end result is an area described as being hypovascular, hypocellular, and hypoxic, with minimal ability to withstand trauma (e.g., dental extraction, alveoloplasty) or to be repaired [81-83]. However, it should be noted that the degree, progression, and irreversibility of these changes are thought to be dose related [75]. In fact, osteoradionecrosis (ORN) is not a common complication of radiotherapy, and the incidence in the literature has been reported to range from $1 \%$ to $37.5 \%$ [61]. A representative 30-year retrospective study of 830 patients showed a collective rate of only $8.2 \%$ [84]. There has also been report that the incidence of ORN is on a decline over the past 20 years, which may be explained by the advent of high-energy radiation sources $[75,85]$. The ORN contains a wide range of clinical presentations which vary from a small stable asymptomatic region of exposed bone to a full-scale ORN that is accompanied by severe pain, foulsmelling necrotic bone of green-grey color, and suppuration [61]. In general, elective oral surgical procedures such as extractions or soft tissue surgeries are contraindicated within the irradiated field [7]. 
Currently, there is little data on the effects of ionizing radiation on teeth. Results from literature appear to be conflicting as to the differential decalcification rates between irradiated and nonirradiated teeth. However, it is widely agreed that the dental pulp of patients who received radiotherapy will demonstrate reduced vascularity, accompanied by fibrosis and atrophy [86]. Pulpal response to trauma, dental procedures, and bacterial assaults maybe compromised, but tolerance to pain seems to increase. The secretory mechanism of odontoblasts may also be affected as excessive osteodentine formation was observed in irradiated rats [87, 88]. With regard to tooth development, the timing of exposure is crucial; tooth bud may be destroyed if irradiation occurs before significant calcification, while growth may be retarded and enamel and dentine irregularities result if exposure happens during a later stage of development [86].

Under direct assault of the ionizing radiation, the TMJ and the muscles of mastication may ultimately undergo fibrosis and contracture resulting in trismus [89]. According to the literature, about $5 \%$ to $38 \%$ of the patients develop trismus after receiving radiation therapy for head and neck cancer [90, 91]. Clinically, trismus manifests as the gradual inability to open the mouth for normal functions; the onset of reduced interincisal opening is generally noted at 9 weeks after radiotherapy. A rate of $2.4 \%$ loss per month was observed in the following 9 months, and a $32 \%$ reduction in the mean interincisal opening was observed after 4 years [92]. Although speech articulation is not adversely affected, this painless condition could make mastication and oral intake of food particularly problematic. The implication is significantly more profound in the case of denture wearers as they may be unable to insert their prostheses and new ones cannot be satisfactorily made due to restricted access and range of jaw motions [75]. Oral hygiene is also severely compromised.

3.5. Complications Associated with HSCT. HSCT, once viewed as experimental decades ago, has since advanced as a customary treatment protocol for a variety of malignancies. HSCT can be categorized into allogenic and autologous: the former is where bone marrow is harvested from a histocompatible donor while the latter is from the patient's own; both are now regularly performed and considered standard of care for selected malignancies [93]. The risk of oral complications from HSCT is comparable to that of conventional chemotherapeutic treatment; patients receiving autologous transplant exhibit possibly slightly higher risk while those undergoing allogeneic graft may face cumbersome complications due to the infusion of donor's stem cells [94-96]. In general, patients undergoing HSCT are at high risk of bacterial (including those of periodontal origin), fungal (particularly Candida), and viral (e.g., HSV, VZV, and CMV) infections [97-106]. Also, there has been report of hairy leukoplakia in humanimmunodeficiency-virus- (HIV-) negative HSCT patients [107]. Potentially life-threatening complications from preexisting periodontitis have also been implicated from cultures of atypical pathogenic organisms isolated from disease sites; the importance of establishing healthy periodontal status

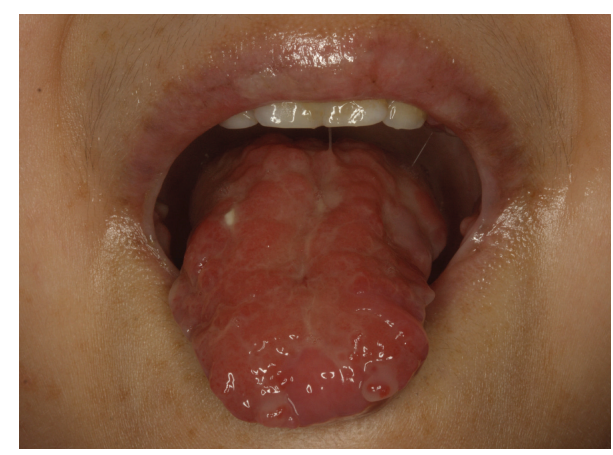

FIGURE 4: Soft tissue distortion in a patient with chronic GVHD.

before cancer therapy could not have been emphasized more [108-110].

Perhaps, of particular concern is the graft versus host disease (GVHD). GVHD is the most important complication of allogeneic transplantation. It occurs via an immunological reaction where the transplanted "graft" cells (donor lymphocytes) recognize the tissues of the "host" (the recipient) as foreign. GVHD can be acute or chronic [111]. Acute form of GVHD usually occurs within a few weeks of the transplantation. It damages the skin, gut, and liver. Typical signs and symptoms may include nausea, vomiting, abdominal pain, diarrhea, bloody stool, and jaundice [21]. The main risk factor is the major histocompatibility antigens (HLA) mismatch; it has been shown that, if prophylaxis is not provided, acute GVHD can affect almost every recipient [112]. Chronic GVHD may immediately follow the acute stage or may occur several months later. It is associated with loss of self-tolerance and symptomatically resembles scleroderma or Sjögren's syndrome [113]. Chronic GVHD is characterized by bronchiolitis, keratoconjunctivitis sicca, esophageal stricture, malabsorption, cholestasis, hematocytopenia, and generalized immunosuppression [21]. The oral manifestation of GVHD varies with the severity of the condition and is associated with a spectrum of presentations. In general, clinical or subclinical chronic GVHD exhibits features that include mild oral mucosal erythema, desquamative gingivitis, loss of lingual papillae, lichenoid hyperkeratosis, and xerostomia (Figure 4), whereas acute GVHD patients may encounter painful desquamation and ulcerative-pseudomembranous reactions. Erythema, angular cheilitis, and lichenoid-like changes have also been observed [111].

\section{Present Practice and Therapeutic Options}

Although priority is often given to the treatment of the malignancy itself, focus should also be directed at prevention and amelioration of complications that may occur as a result of the disease and/or its treatment. A thorough head and neck evaluation, oral soft and hard tissue examination, and the associated intraoral radiographs are all essential parts of the initial dental visit for cancer patients. The goal of such visit is to remove and document any preexisting acute and chronic pathological conditions, for example, periodontal 
and periapical pathology, residual cysts, and impacted or partially erupted teeth. Through consultation with the patient's primary-care physician and revision of his/her medical status, oral surgery, intermediate or definitive restorations, and oral prophylaxis procedures may be performed safely, and if required, under intravenous sedation and/or local/general anesthesia [7]. It should be noted that evaluation, treatment, and prevention of any preexisting oral and dental pathology contribute significantly to the overall favourable treatment outcome for cancer patients; for this reason, the patient's oral health status should be stabilized/optimized for minimally predictable complications $[7,114]$.

In the following section, some therapeutic options for the management of common oral complications of cancer treatment are presented. Through this general guide, the author of this paper sincerely hopes that general dental practitioners can benefit from it and may find it useful in ameliorating some of the painful oral complications of cancer therapy.

4.1. Mucositis. Presently, there is no medication proven to be able to successfully eliminate mucositis [4]. However, painful symptoms can still be managed and oral discomfort alleviated so as to improve the patient's quality of life. The current approach focuses on the management of pain and the encouragement of eating, especially in chemotherapyinduced mucositis [115]. One strategy on pain relief pertains to the use of an oral solution mixture known as "Magic Mouthwash;" it is composed of diphenhydramine, viscous lidocaine, bismuth, subsalicylate, and corticosteroids [116]. It is said to relieve acute pain and reduce inflammation, making oral consumption of food much easier. Yet, highgrade mucositis pain is commonly relieved with potent analgesic medications such as opioids [117]. Alternatively, a number of recent studies have investigated the potential of newer therapeutic interventions, in particular, concerning the efficacy of growth factors and cytokines in curtailing the development of high-grade mucositis and reducing the duration of the lesions. Palifermin (Kepivance; Amgen, Thousand Oaks, CA, USA), a recombinant human keratinocyte growth factor vigorously researched, shows much promise in reducing the frequency of high-grade (WHO grade 3 or 4) mucositis [118]. Furthermore, palifermin has been demonstrated to decrease the duration of mucositis, thereby lessening the use of parenteral nutrition and entailing higher scores for physical and functional well-being [118]. In a separate study, the beneficial effect of palifermin as preventive therapy for mucositis has been confirmed [119]. Nevertheless, the drug is not without its side effect; taste alteration in patients treated with palifermin has been reported [120].

Other practical therapies for mucositis are also showing promises, though evidence and data from the literature are limited. One method widely used among oncologists is the application of ice chips to the mouth every 30 minutes for prevention and treatment of oral mucositis in patients undergoing chemotherapy. The rationale of oral cryotherapy is that, through vasoconstriction, the release of chemotherapeutic drugs to the mucosal epithelium is reduced [121]. Perhaps, an effective preventive measure of recent interest is the use of low level laser therapy (LLLT). Various studies have demonstrated the potential benefits of LLLT in its ability to reduce the rates of WHO severe grade mucositis $[121,122]$. Other novel methods and experimental approaches include a formulation containing the amino acid L-glutamine and the hormone, leptin; both have been shown to have a positive impact on the development of mucositis [123-126].

4.2. Oral Infections. Often, cancer treatments can negatively affect the patient's immune system. With his/her immune response suppressed, opportunistic infections can contribute to significant morbidity and mortality.

4.2.1. Bacterial Infections. Normal oral flora comprises of a variety of bacteria, some of which may become pathogenic with immunosuppression. According to Rautemaa and colleagues, sepsis of unknown origin may possibly be the result of oral infections (e.g., Viridans Streptococcus, Prevotella species, Fusobacterium, Actinobacillus actinomycetemcomitans, and Actinomyces species) [127]. Nonetheless, the infections are usually localized to oral mucosa and can be treated with a combination of penicillin and metronidazole, followed by routine dental procedures if necessary [4]. Given the patient's condition, meticulous oral hygiene practice is paramount. Bacteria may be removed from the teeth by gentle brushing with a soft bristle tooth brush and flossing. One may consider using an antimicrobial mouthwash as an adjunct. In the case where brushing becomes difficult (e.g., mucosal damage), a chlorhexidine-containing mouthwash is generally recommended [6].

4.2.2. Candidiasis. According to Lalla and colleagues, the prevalence of oral fungal infection from all forms of cancer therapy was about $7.5 \%$ before treatment, $40 \%$ during treatment, and 30\% after treatment [128]. Yet, a Cochrane metaanalysis has concluded that there is currently insufficient evidence from the literature to make a recommendation for or against the treatment of oral candidiasis with antifungal agents in patients undergoing cancer treatment [129]. Nevertheless, it is the responsibility of the general dental practitioner to ease the patient's suffering, and that entails morbidity reduction and systemic infection prevention. It should be noted that although topical antifungal agents are commonly prescribed for their lower risk of side effects and drug interactions, literature support of their efficacy is inconsistent [128]. According to the guidelines provided by the Infectious Disease Society of America (IDSA), clotrimazole troches and nystatin pastilles are the first line drugs for mild oropharyngeal candidiasis [130]. However, they may be difficult to apply in situations such as hyposalivation and/or mucositis in which the experience can be traumatic; thus, an alternate solution is to use nystatin rinses [128]. With the high relapse rate of topical agents, one may also consider systemic antifungal agents [131]. In fact, the IDSA guidelines recommend the use of systemic fluconazole (100-200 mg/day for 2 weeks) (Diflucan; Pfizer Labs, New York, NY, USA) for the management of moderate to severe infections [130]. In fluconazole resistant cases, itraconazole capsules $(200 \mathrm{mg} /$ day for 2-4 weeks) or itraconazole oral solution (200 mg/day for 
2 weeks) may also be considered [128]. As a second line drug, posaconazole (Noxafil; Merck \& CO., Whitehouse Station, NJ, USA) is suggested by the IDSA [130]. In situations where the disease becomes refractory, a broader spectrum drug of a more potent nature such as voriconazole (Vfend; Pfizer Labs, New York, NY, USA), caspofungin (Cancidas; Merck \& CO., Whitehouse Station, NJ, USA), and amphotericin B (Fungizone; Bristol-Myers Squibb Co., Princeton, NJ, USA) is suggested. Note that voriconazole has been reported to be associated with severe photosensitivity, and possibly an increased risk of skin cancer, whereas amphotericin B is known for its systemic side effects, for example, high fever $[128,130,132]$.

Whereas the aforementioned modalities are all aimed at treating oral candidiasis, the potential benefits of prophylaxis should not be ignored, particularly in severely immunosuppressed and/or neutropenic patients. From a Cochrane review, there is reasonably good evidence from randomized controlled trials that drugs absorbed from the GI tract prevent candidiasis in cancer patients [129]. A number of studies have demonstrated the efficacy of prophylactic use of fluconazole, itraconazole, posaconazole, and intravenous micafungin (Mycamine; Astellas Pharma US, Inc., Deerfield, IL, USA) in reducing the prevalence of all clinical fungal infections during cancer therapy [128, 133-137]. Interestingly, however, there has been little evidence from the literature on the relative cost effectiveness of systemic versus topical prophylaxis for oral fungal infections [129].

4.2.3. Viral Infections. HSV is quite prevalent in the general population. In the majority of the cases, HSV infection stems from latent viral reactivation. Current literature suggests that immunosuppression due to chemotherapy is the main contributive factor, with prevalence approaching $40 \%$. Neutropenic patients with hematological malignancies are at the greatest risk, that is, 50\%, during treatment [138]. Presently, acyclovir (Zovirax; GlaxoSmithKline Pharmaceuticals, Research Triangle Park, NC, USA) and valacyclovir (Valtrex; GlaxoSmithKline Pharmaceuticals, Research Triangle Park, NC, USA) have both been shown to be equally efficacious in prevention and treatment of HSV [139]. Oral prophylaxis can be accomplished with acyclovir at the dose of 200-800 $\mathrm{mg}$ thrice a day or valacyclovir at the dose of $500 \mathrm{mg}$ twice a day [139-141]. During treatment, acyclovir may be used intravenously at the dose of $5 \mathrm{mg} / \mathrm{kg}$ every 8 hours or perorally $200-400 \mathrm{mg} \mathrm{3-5}$ times a day; on the other hand, the unavailability of intravenous valacyclovir limits its use to the oral dosing regimen of 500-1000 twice a day [139]. An alternative is famciclovir (Famvir; Novartis Pharmaceuticals Corp., East Hanover, NJ, USA). In case of drug resistance, intravenous foscarnet (Foscavir; AstraZeneca, Wilmington, NC, USA) and cidofovir (Vistide; Gilead Sciences, Inc., Foster City, CA, USA) may be used [142].

Of particular concern is oral hairy leukoplakia (OHL), a result of Epstein-Barr virus infection, commonly seen in HIV infected individuals. However, OHL can also manifest in immunocompromised patients (e.g., patients under cancer treatment) who are HIV negative. Reports have shown that
OHL can occur in patients under chemotherapy for acute myelogenous leukemia, acute lymphocytic leukemia, and multiple myeloma, as well as in patients under corticosteroid regimen for gastrointestinal stromal tumor [143-147]. At present, there is no universal therapy for the management of OHL; however, high dose oral valacyclovir may be used safely and effectively [148]. Alternatively, topical treatment, that is, $25 \%$ podophyllin resin alone or in combination with $5 \%$ topical acyclovir, and gentian violet could be considered [149-151].

4.3. Xerostomia. Patients who have undergone head and neck cancer radiotherapy tend to have long-term side effects which are xerostomia and hyposalivation, resulting in further complications such as increased caries incidence and loss of taste [5]. It is advisable for the patient who has dry mouth to take frequent sips of water (every 10 minutes) and melt ice chips in mouth for comfort. Additionally, one may consider the use of artificial saliva spray (e.g., Xerotin, MoiStir, Salivart, Xero-Lube, Saliva Orthana) and mouth moisturizing gel (e.g., Biotène Oral Balance). The lips may well be lubricated with petroleum jelly or a lanolin-containing preparation (e.g., BioXtra moisturizing gel). Patients should be cautioned against coffee, tea, soft drinks with caffeine, and commercial mouth rinses with alcohol as they can dehydrate the mouth. Alcohol-free mouth rinses (e.g., BioXtra alcoholfree mouthrinse, Biotène mouthwash, and OralSeven moisturising mouthwash) are recommended. Residual salivary gland activity and salivary flow rate may be increased by saliva stimulating tablets (SST) and medications like pilocarpine (Salagen, $5 \mathrm{mg}$, thrice a day), respectively. Finally, patients are recommended to use sorbitol- or xylitol-based chewing gum for salivary flow stimulation and caries arresting.

4.4. Dysgeusia. It is estimated that about $50 \%$ to $75 \%$ of the cancer patients receiving chemotherapy, radiotherapy, or both will suffer from distorted or impaired ability to taste $[152,153]$. While patients under radiation treatment tend to suffer most from dysgeusia, its severity is highly correlated to the cumulative radiation dose. Mild dysgeusia is generally well tolerated; nevertheless, impaired ability to taste, which affects appetite, reduces caloric intake, induces weight loss, and hampers nutritional status, can exert great impact on the patient's quality of life [5]. At present, several strategies have been proposed for the management of dysgeusia. Although clinical efficacy of zinc supplementation has been quite variable, its use has been suggested by several studies to ameliorate the debilitating effects of dysgeusia [154]. The rationale is such that zinc element may be structurally important in the proteins responsible for regulating the taste bud pores [5]. Additionally, one may also consider supplementing diet with vitamin $\mathrm{D}$ as it was reported that patients suffering from dysgeusia made improvement from it [155]. Sometimes, dietary counselling may have more impact on long-term dysgeusia and improve patient outcome [156, 157]. Several simple methods have been utilized by nutritionists for symptomatic patients [153]. Patients are advised to drink plenty of fluids during meal, as such would enable the dissolution of taste 
components in the food and facilitate their translocation to taste buds. Food should be chewed slowly and thoroughly to release more flavours and stimulate saliva production; this is especially crucial if the patient is also suffering from dry mouth where saliva is important to taste. Patients should also switch foods during meals to prevent adaptation of taste receptors while taking care to maintain a balanced diet at the same time [152].

\section{Conflict of Interests}

The author declares that there is no conflict of interests regarding the publication of this paper.

\section{Acknowledgment}

This work was supported by the Committee on Research and Conference Grants, The University of Hong Kong (Project no. 10401084).

\section{References}

[1] Centers for Disease Controland Prevention, "Ttop ten cancers," 2009, http://apps.nccd.cdc.gov/uscs/toptencancers.aspx.

[2] R. Siegel, D. Naishadham, and A. Jemal, "Cancer statistics, 2012," CA-A Cancer Journal for Clinicians, vol. 62, no. 1, pp. 10-29, 2012.

[3] American Cancer Society, "Cancer Facts \& Figures," 2013, http://www.cancer.org/acs/groups/content/@epidemiologysurveilance/documents/document/acspc-036845.pdf.

[4] D. D. Mosel, R. L. Bauer, D. P. Lynch, and S. T. Hwang, "Oral complications in the treatment of cancer patients," Oral Diseases, vol. 17, no. 6, pp. 550-559, 2011.

[5] V. K. Joshi, "Dental treatment planning and management for the mouth cancer patient," Oral Oncology, vol. 46, no. 6, pp. 475479, 2010.

[6] C. H. L. Hong, J. J. Napeñas, B. D. Hodgson et al., "A systematic review of dental disease in patients undergoing cancer therapy," Supportive Care in Cancer, vol. 18, no. 8, pp. 1007-1021, 2010.

[7] M. S. Chambers, B. B. Toth, J. W. Martin, T. J. Fleming, and J. C. Lemon, "Oral and dental management of the cancer patient: prevention and treatment of complications," Supportive Care in Cancer, vol. 3, no. 3, pp. 168-175, 1995.

[8] M. Miller and N. Kearney, "Oral care for patients with cancer: a review of the literature," Cancer Nursing, vol. 24, no. 4, pp. 241254, 2001.

[9] G. J. Barker, J. B. Epstein, K. B. Williams, M. Gorsky, and J. E. Raber-Durlacher, "Current practice and knowledge of oral care for cancer patients: a survey of supportive health care providers," Supportive Care in Cancer, vol. 13, no. 1, pp. 32-41, 2005.

[10] I. Al-Dakkak, "The association between cancer treatments and oral diseases," Evidence-Based Dentistry, vol. 12, no. 1, pp. 15-16, 2011.

[11] A. Kolokythas, "Long-term surgical complications in the oral cancer patient: a comprehensive review. Part I," Journal of Oral \& Maxillofacial Research, vol. 1, no. 3, article el, 2010.

[12] I. Carreca, L. Balducci, and M. Extermann, "Cancer in the older person,” Cancer Treatment Reviews, vol. 31, no. 5, pp. 380-402, 2005.
[13] B. C. López, C. G. Esteve, and M. G. S. Pérez, "Dental treatment considerations in the chemotherapy patient," Journal of Clinical and Experimental Dentistry, vol. 3, pp. e31-e42, 2011.

[14] N. Toscano, D. Holtzclaw, I. A. Hargitai et al., "Oral implications of cancer chemotherapy," The Journal of Implant \& Advanced Clinical Dentistry, vol. 1, pp. 51-69, 2009.

[15] M. P. López Galindo, J. V. Bagán, Y. Jiménez Soriano, F. Alpiste, and C. Camps, "Clinical evaluation of dental and periodontal status in a group of oncological patients before chemotherapy," Medicina Oral, Patologia Oral y Cirugia Bucal, vol. 11, no. 1, pp. 17-21, 2006.

[16] F. Caribé Gomes, E. Chimenos Küstner, J. López López, F. Finestres Zubeldia, and B. Guix Melcior, "Dental management of the complications of radio and chemotherapy in oral cancer," Medicina Oral, vol. 8, no. 3, pp. 178-187, 2003.

[17] A. Vissink, J. Jansma, F. K. L. Spijkervet, F. R. Burlage, and R. P. Coppes, "Oral sequelae of head and neck radiotherapy," Critical Reviews in Oral Biology and Medicine, vol. 14, no. 3, pp. 199-212, 2003.

[18] A. C. Begg, F. A. Stewart, and C. Vens, "Strategies to improve radiotherapy with targeted drugs," Nature Reviews Cancer, vol. 11, no. 4, pp. 239-253, 2011.

[19] J. Bourhis, A. Etessami, and A. Lusinchi, "New trends in radiotherapy for head and neck cancer," Annals of Oncology, vol. 16, no. 2, pp. ii255-ii257, 2005.

[20] A. M. Kielbassa, W. Hinkelbein, E. Hellwig, and H. MeyerLückel, "Radiation-related damage to dentition," The Lancet Oncology, vol. 7, no. 4, pp. 326-335, 2006.

[21] E. A. Copelan, "Hematopoietic stem-cell transplantation," The New England Journal of Medicine, vol. 354, no. 17, pp. 1813-1826, 2006.

[22] K. Yamagata, K. Onizawa, T. Yanagawa et al., "A prospective study to evaluate a new dental management protocol before hematopoietic stem cell transplantation," Bone Marrow Transplantation, vol. 38, no. 3, pp. 237-242, 2006.

[23] B. Toth and T. J. Fleming, "Oral care for the patient with cancer," Highlights Antineoplastic Drugs, vol. 8, pp. 27-35, 1990.

[24] B. Toth, J. W. Martin, and T. J. Fleming, "Oral and dental care associated with cancer therapy," Cancer Bulletin, vol. 43, pp. 397-402, 1991.

[25] A. Kolokythas, "Long-term surgical complications in the oral cancer patient: a comprehensive review. part II," Journal of Oral \& Maxillofacial Research, vol. 1, article e2, 2010.

[26] G. R. LaBlance, K. Kraus, and K. F. Steckol, "Rehabilitation of swallowing and communication following glossectomy," Rehabilitation Nursing, vol. 16, no. 5, pp. 266-270, 1991.

[27] R. Massengill Jr., S. Maxwell, and K. Pickrell, "An analysis of articulation following partial and total glossectomy," Journal of Speech and Hearing Disorders, vol. 35, no. 2, pp. 170-173, 1970.

[28] B. R. Pauloski, J. A. Logemann, L. A. Colangelo et al., "Surgical variables affecting speech in treated patients with oral and oropharyngeal cancer," Laryngoscope, vol. 108, no. 6, pp. 908916, 1998.

[29] B. Roa Pauloski, J. A. Logemann, A. W. Rademaker et al., "Speech and swallowing function after anterior tongue and floor of mouth resection with distal flap reconstruction," Journal of Speech and Hearing Research, vol. 36, no. 2, pp. 267-276, 1993.

[30] A. Kolokythas, "Long-term surgical complications in the oral cancer patient: a comprehensive review. Part I," Journal of Oral and Maxillofacial Surgery, vol. 1, article e1, 2010. 
[31] M. L. Urken, D. Buchbinder, H. Weinberg et al., "Functional evaluation following microvascular oromandibular reconstruction of the oral cancer patient: a comparative study of reconstructed and nonreconstructed patients," Laryngoscope, vol. 101, no. 9, pp. 935-950, 1991.

[32] D. A. Curtis, O. Plesh, A. J. Miller et al., "A comparison of masticatory function in patients with or without reconstruction of the mandible," Head and Neck, vol. 19, no. 4, pp. 287-296, 1997.

[33] C. J. Kerawala, "Complications of head and neck cancer surgery-prevention and management," Oral Oncology, vol. 46, no. 6, pp. 433-435, 2010.

[34] D. D. Kim and R. A. Ord, "Complications in the treatment of head and neck cancer," Oral and Maxillofacial Surgery Clinics of North America, vol. 15, no. 2, pp. 213-227, 2003.

[35] E. B. Neovius, M. G. Lind, and F. G. Lind, "Hyperbaric oxygen therapy for wound complications after surgery in the irradiated head and neck: a review of the literature and a report of 15 consecutive patients," Head and Neck, vol. 19, no. 4, pp. 315-322, 1997.

[36] N. Treister and S. Sonis, "Mucositis: biology and management," Current Opinion in Otolaryngology and Head and Neck Surgery, vol. 15, no. 2, pp. 123-129, 2007.

[37] C. H. Hong and M. daFonseca, "Considerations in the pediatric population with cancer," Dental Clinics of North America, vol. 52, no. 1, pp. 155-181, 2008.

[38] S. Borbasi, K. Cameron, B. Quested, I. Olver, B. To, and D. Evans, "More than a sore mouth: patients' experience of oral mucositis," Oncology Nursing Forum, vol. 29, no. 7, pp. 1051-1057, 2002.

[39] J. C. Murray, J. K. H. Chiu, S. R. Dorfman, and A. K. Ogden, "Epiglottitis following preparation for allogeneic bone marrow transplantation," Bone Marrow Transplantation, vol. 15, no. 6, pp. 997-998, 1995.

[40] S. T. Sonis, "A biological approach to mucositis," Journal of Supportive Oncology, vol. 2, no. 1, pp. 21-32, 2004.

[41] K. H. Chaimberg and J. P. Cravero, "Mucositis and airway obstruction in a pediatric patient," Anesthesia and Analgesia, vol. 99, no. 1, pp. 59-61, 2004.

[42] G. Fadda, G. Campus, and P. Lugliè, "Risk factors for oral mucositis in paediatric oncology patients receiving alkylant chemotherapy," BMC Oral Health, vol. 6, article 13, 2006.

[43] World Health Organization, Handbook For Reporting Results of Cancer Treatment, World Health Organization, Geneva, Switzerland, 1979.

[44] S. T. Sonis, L. S. Elting, D. Keefe et al., "Perspectives on cancer therapy-induced mucosal injury: pathogenesis, measurement, epidemiology, and consequences for patients," Cancer, vol. 100, no. 9, pp. 1995-2025, 2004.

[45] E. B. Rubenstein, D. E. Peterson, M. Schubert et al., "Clinical practice guidelines for the prevention and treatment of cancer therapy-induced oral and gastrointestinal mucositis., Cancer, vol. 100, pp. 2026-2046, 2004.

[46] W. J. Köstler, M. Hejna, C. Wenzel, and C. C. Zielinski, “Oral mucositis complicating chemotherapy and/or radiotherapy: options for prevention and treatment," CA-A Cancer Journal for Clinicians, vol. 51, no. 5, pp. 290-315, 2001.

[47] C. E. Saadeh, "Chemotherapy- and radiotherapy-induced oral mucositis: review of preventive strategies and treatment," Pharmacotherapy, vol. 25, no. 4, pp. 540-554, 2005.

[48] M. Karthaus, C. Rosenthal, and A. Ganser, "Prophylaxis and treatment of chemo- and radiotherapy-induced oral mucositis-are there new strategies?" Bone Marrow Transplantation, vol. 24, no. 10, pp. 1095-1108, 1999.

[49] M. A. Huber and G. T. Terezhalmy, "The medical oncology patient," Quintessence International, vol. 36, no. 5, pp. 383-402, 2005.

[50] J. B. Epstein and M. M. Schubert, "Oropharyngeal mucositis in cancer therapy:Review of pathogenesis, diagnosis, and management," Oncology, vol. 17, no. 12, pp. 1767-1779, 2003.

[51] J. Crawford, D. C. Dale, and G. H. Lyman, "Chemotherapyinduced neutropenia, risks, consequences, and new directions for their management," Cancer, vol. 100, pp. 228-237, 2004.

[52] A. Heimdahl, "Prevention and management of oral infections in cancer patients," Supportive Care in Cancer, vol. 7, no. 4, pp. 224-228, 1999.

[53] J. B. Epstein and A. W. Chow, "Oral complications associated with immunosuppression and cancer therapies," Infectious Disease Clinics of North America, vol. 13, no. 4, pp. 901-923, 1999.

[54] M. Glick and M. A. Siegel, "Viral and fungal infections of the oral cavity in immunocompetent patients," Infectious Disease Clinics of North America, vol. 13, no. 4, pp. 817-831, 1999.

[55] M. T. Montgomery, S. W. Redding, and C. F. LeMaistre, "The incidence of oral herpes simplex virus infection in patients undergoing cancer chemotherapy," Oral Surgery Oral Medicine and Oral Pathology, vol. 61, no. 3, pp. 238-242, 1986.

[56] I. T.-L. Tang and D. H. Shepp, "Herpes simplex virus infection in cancer patients: prevention and treatment," Oncology, vol. 6, no. 7, pp. 101-109, 1992.

[57] J. B. Epstein, C. Sherlock, J. L. Page, J. Spinelli, and G. Phillips, "Clinical study of herpes simplex virus infection in leukemia," Oral Surgery Oral Medicine and Oral Pathology, vol. 70, no. 1, pp. 38-43, 1990.

[58] P. Reusser, "Current concepts and challenges in the prevention and treatment of viral infections in immunocompromised cancer patients," Supportive Care in Cancer, vol. 6, no. 1, pp. 3945, 1998 .

[59] P. B. Lockhart and S. T. Sonis, "Relationship of oral complications to peripheral blood leukocyte and platelet counts in patients receiving cancer chemotherapy," Oral Surgery Oral Medicine and Oral Pathology, vol. 48, no. 1, pp. 21-28, 1979.

[60] J. A. Caprini and S. F. Sener, "Altered coagulability in cancer patients," CA-A Cancer Journal for Clinicians, vol. 32, no. 3, pp. $162-172,1982$.

[61] J. J. Sciubba and D. Goldenberg, "Oral complications of radiotherapy," The Lancet Oncology, vol. 7, no. 2, pp. 175-183, 2006.

[62] J. Herrstedt, "Prevention and management of mucositis in patients with cancer," International Journal of Antimicrobial Agents, vol. 16, no. 2, pp. 161-163, 2000.

[63] K. L. Mossman, "Quantitative radiation dose-response relationships for normal tissues in man. II. Response of the salivary glands during radiotherapy," Radiation Research, vol. 95, no. 2, pp. 392-398, 1983.

[64] K. Mossman, A. Shatzman, and J. Chencharick, "Long-term effects of radiotherapy on taste and salivary function in man," International Journal of Radiation Oncology Biology Physics, vol. 8, no. 6, pp. 991-997, 1982.

[65] P. Kaplan, "Mantle irradiation of the major salivary glands," The Journal of Prosthetic Dentistry, vol. 54, no. 5, pp. 681-686, 1985.

[66] P. J. Hughes, P. M. Scott, J. Kew et al., "Dysphagia in treated nasopharyngeal cancer," Head \& Neck, vol. 22, no. 4, pp. 393$397,2000$. 
[67] V. Ramirez-Amador, S. Silverman Jr., P. Mayer, M. Tyler, and J. Quivey, "Candidal colonization and oral candidiasis in patients undergoing oral and pharyngeal radiation therapy," Oral Surgery, Oral Medicine, Oral Pathology, Oral Radiology, and Endodontics, vol. 84, no. 2, pp. 149-153, 1997.

[68] M. S. Kies, D. J. Haraf, F. Rosen et al., "Concomitant infusional paclitaxel and fluorouracil, oral hydroxyurea, and hyperfractionated radiation for locally advanced squamous head and neck cancer," Journal of Clinical Oncology, vol. 19, no. 7, pp. 19611969, 2001.

[69] J. W. Schweiger, "Oral complications following radiation therapy: a five-year retrospective report," The Journal of Prosthetic Dentistry, vol. 58, no. 1, pp. 78-82, 1987.

[70] I. D. Mandel, "The role of saliva in maintaining oral homeostasis," The Journal of the American Dental Association, vol. 119, no. 2, pp. 298-304, 1989.

[71] A. Eisbruch, H. M. Kim, J. E. Terrell, L. H. Marsh, L. A. Dawson, and J. A. Ship, "Xerostomia and its predictors following parotidsparing irradiation of head-and-neck cancer," International Journal of Radiation Oncology Biology Physics, vol. 50, no. 3, pp. 695-704, 2001.

[72] J. M. Roesink, A. W. T. Konings, C. H. J. Terhaard, J. J. Battermann, H. H. Kampinga, and R. P. Coppes, "Preservation of the rat parotid gland function after radiation by prophylactic pilocarpine treatment: radiation dose dependency and compensatory mechanisms," International Journal of Radiation Oncology Biology Physics, vol. 45, no. 2, pp. 483-489, 1999.

[73] S. R. Porter, C. Scully, and A. M. Hegarty, "An update of the etiology and management of xerostomia," Oral Surgery, Oral Medicine, Oral Pathology, Oral Radiology, and Endodontics, vol. 97, no. 1, pp. 28-46, 2004.

[74] M. S. Chambers, A. S. Garden, M. S. Kies, and J. W. Martin, "Radiation-induced xerostomia in patients with head and neck cancer: pathogenesis, impact on quality of life, and management," Head and Neck, vol. 26, no. 9, pp. 796-807, 2004.

[75] N. Andrews and C. Griffiths, "Dental complications of head and neck radiotherapy: Part 1," Australian Dental Journal, vol. 46, no. 2, pp. 88-94, 2001.

[76] A. D. Conger, "Loss and recovery of taste acuity in patients irradiated to the oral cavity," Radiation Research, vol. 53, no. 2, pp. 338-347, 1973.

[77] R. R. Million, "The effect of radiation on normal tissues of the head and neck," in Management of Head and Neck Cancer: a Multidisciplinary Approach, N. J. Cassisi, Ed., J. P. Lippincott, Philadelphia, Pa, USA, 1984.

[78] L. R. Brown, S. Dreizen, S. Handler, and D. A. Johnston, "Effect of radiation induced xerostomia on human oral microflora," Journal of Dental Research, vol. 54, no. 4, pp. 740-750, 1975.

[79] C. Scully, J. Epstein, and S. Sonis, "Oral mucositis: a challenging complication of radiotherapy, chemotherapy, and radiochemotherapy. Part 2: diagnosis and management of mucositis," Head and Neck, vol. 26, no. 1, pp. 77-84, 2004.

[80] S. Dreizen, "Description and incidence of oral complications," NCI Monographs, no. 9, pp. 11-15, 1990.

[81] R. E. Marx, "Osteoradionecrosis: a new concept of its pathophysiology," Journal of Oral and Maxillofacial Surgery, vol. 41, no. 5, pp. 283-288, 1983.

[82] J. Beumer III, S. Silverman Jr., and S. B. Benak Jr., "Hard and soft tissue necroses following radiation therapy for oral cancer," The Journal of Prosthetic Dentistry, vol. 27, no. 6, pp. 640-644, 1972.
[83] J. B. Epstein, G. Rea, F. L. W. Wong, J. Spinelli, and P. StevensonMoore, "Osteonecrosis: study of the relationship of dental extractions in patients receiving radiotherapy," Head and Neck Surgery, vol. 10, no. 1, pp. 48-54, 1987.

[84] T. Reuther, T. Schuster, U. Mende, and A. C. Kübler, "Osteoradionecrosis of the jaws as a side effect of radiotherapy of head and neck tumour patients-a report of a thirty year retrospective review," International Journal of Oral and Maxillofacial Surgery, vol. 32, no. 3, pp. 289-295, 2003.

[85] G. Studer, K. W. Grätz, and C. Glanzmann, “Osteoradionecrosis of the Mandibula in Patients Treated with Different Fractionations," Strahlentherapie und Onkologie, vol. 180, no. 4, pp. 233240, 2004.

[86] J. Beumer III, T. Curtis, and R. E. Harrison, "Radiation therapy of the oral cavity: sequelae and management, Part I," Head and Neck Surgery, vol. 1, no. 4, pp. 301-312, 1979.

[87] W. K. Collett and J. C. Thonard, "The effect of fractional radiation on dentinogenesis in the rat," Journal of Dental Research, vol. 44, pp. 84-90, 1965.

[88] H. S. Koppang, "Studies on the radiosensitivity of the rat incisor," Odontologisk Tidskrift, vol. 75, no. 5, pp. 413-450, 1967.

[89] A. Vissink, J. Jansma, F. K. L. Spijkervet, F. R. Burlage, and R. P. Coppes, "Oral sequelae of head and neck radiotherapy," Critical Reviews in Oral Biology and Medicine, vol. 14, no. 3, pp. 199-212, 2003.

[90] F. Thomas, F. Ozanne, G. Mamelle, P. Wibault, and F. Eschwege, "Radiotherapy alone for oropharyngeal carcinomas: the role of fraction size ( 2 Gy vs $2.5 \mathrm{~Gy}$ ) on local control and early and late complications," International Journal of Radiation Oncology Biology Physics, vol. 15, no. 5, pp. 1097-1102, 1988.

[91] R. Steelman and J. Sokol, "Quantification of trismus following irradiation of the temporomandibular joint," Missouri Dental Journal, vol. 66, no. 6, pp. 21-23, 1986.

[92] C.-J. Wang, E.-Y. Huang, H.-C. Hsu, H.-C. Chen, F.-M. Fang, and C.-Y. Hsiung, "The degree and time-course assessment of radiation-induced trismus occurring after radiotherapy for nasopharyngeal cancer," Laryngoscope, vol. 115, no. 8, pp. 14581460, 2005.

[93] D. Eisen, J. Essell, and E. R. Broun, "Oral cavity complications of bone marrow transplantation," Seminars in Cutaneous Medicine and Surgery, vol. 16, no. 4, pp. 265-272, 1997.

[94] A. Barasch and M. M. Safford, "Management of oral pain in patients with malignant diseases," Compendium, vol. 14, no. 11, pp. 1376-1386, 1993.

[95] R. Collins, G. W. Miller, and J. W. Fay, "Autologous bone marrow transplantation: a review," BUMC Proceedings, vol. 4, no. 2, pp. 3-12, 1991.

[96] W. G. Maxymiw and R. E. Wood, "The role of dentistry in patients undergoing bone marrow transplantation," British Dental Journal, vol. 167, no. 7, pp. 229-234, 1989.

[97] A. P. Barrett and M. Schifter, "Antibiotic strategy in orofa$\mathrm{cial} /$ head and neck infections in severe neutropenia," Oral Surgery, Oral Medicine, Oral Pathology, vol. 77, no. 4, pp. 350355, 1994.

[98] T. Mattsson, A. Heimdahl, G. Dahllof, B. Lonnquist, and O. Ringden, "Oral and nutritional status in allogeneic marrow recipients treated with T-cell depletion or cyclosporine combined with methotrexate to prevent graft- versus-host disease," Oral Surgery Oral Medicine and Oral Pathology, vol. 74, no. 1, pp. 34-40, 1992. 
[99] B. B. Toth, J. W. Martin, M. S. Chambers, K. A. Robinson, and B. S. Andersson, "Oral candidiasis: a morbid sequela of anticancer therapy," Texas Dental Journal, vol. 115, no. 6, pp. 24-29, 1998.

[100] A. T. Brown, J. A. Shupe, R. E. Sims et al., "In vitro effect of chlorhexidine and amikacin on oral gram-negative bacilli from bone marrow transplant recipients," Oral Surgery Oral Medicine and Oral Pathology, vol. 70, no. 6, pp. 715-719, 1990.

[101] C. Birek, B. Patterson, W. C. Maximiw, and M. D. Minden, "EBV and HSV infections in a patient who had undergone bone marrow transplantation: oral manifestations and diagnosis by in situ nucleic acid hybridization," Oral Surgery Oral Medicine and Oral Pathology, vol. 68, no. 5, pp. 612-617, 1989.

[102] F. G. LeVeque, V. Ratanatharathorn, M. E. Dan, B. Orville, D. N. Coleman, and S. Turner, "Oral cytomegalovirus infection in an unrelated bone marrow transplantation with possible mediation by graft-versus-host disease and the use of cyclosporin-A," Oral Surgery, Oral Medicine, Oral Pathology, vol. 77, no. 3, pp. 248-253, 1994.

[103] M. M. Schubert, D. E. Peterson, N. Flournoy, J. D. Meyers, and E. L. Truelove, "Oral and pharyngeal herpes simplex virus infection after allogeneic bone marrow transplantation: analysis of factors associated with infection," Oral Surgery Oral Medicine and Oral Pathology, vol. 70, no. 3, pp. 286-293, 1990.

[104] L. M. Schuchter, J. R. Wingard, S. Piantadosi, W. H. Burns, G. W. Santos, and R. Saral, "Herpes zoster infection after autologous bone marrow transplantation," Blood, vol. 74, no. 4, pp. 14241427, 1989.

[105] J. M. Vose, B. C. Kennedy, P. J. Bierman, A. Kessinger, and J. O. Armitage, "Long-term sequelae of autologous bone marrow or peripheral stem cell transplantation for lymphoid malignancies," Cancer, vol. 69, no. 3, pp. 784-789, 1992.

[106] M. M. Schubert, J. B. Epstein, M. E. Lloid, and E. Cooney, "Oral infections due to Cytomegalovirus in immunocompromised patients," Journal of Oral Pathology and Medicine, vol. 22, no. 6, pp. 268-273, 1993.

[107] J. B. Epstein, C. H. Sherlock, and R. A. Wolber, "Hairy leukoplakia after bone marrow transplantation," Oral Surgery Oral Medicine and Oral Pathology, vol. 75, no. 6, pp. 690-695, 1993.

[108] B. B. Toth, M. S. Chambers, T. J. Fleming, J. C. Lemon, and J. W. Martin, "Minimizing oral complications of cancer treatment," Oncology, vol. 9, no. 9, pp. 851-866, 1995.

[109] B. B. Toth, M. S. Chambers, and T. C. Fleming, "Prevention and management of oral complications associated with cancer therapies: radiotherapy/chemotherapy," Texas Dental Journal, vol. 113, no. 6, pp. 23-29, 1996.

[110] D. E. Peterson, "Pretreatment strategies for infection prevention in chemotherapy patients," NCI Monographs, no. 9, pp. 61-71, 1990.

[111] S. A. Fayle, M. S. Duggal, and S. A. Williams, "Oral problems and the dentist's role in the management of paediatric oncology patients," Dental Update, vol. 19, no. 4, pp. 152-158, 1992.

[112] K. M. Sullivan, H. J. Deeg, and J. Sanders, "Hyperacute graft$\mathrm{v}$-host disease in patients not given immunosuppression after allogeneic marrow transplantation," Blood, vol. 67, no. 4, pp. 1172-1175, 1986.

[113] E. Tivol, R. Komorowski, and W. R. Drobyski, "Emergent autoimmunity in graft-versus-host disease," Blood, vol. 105, no. 12, pp. 4885-4891, 2005.

[114] A. E. Chang, D. F. Hayes, H. I. Pass et al., Oncology: an EvidenceBased Approach, Springer, New York, NY, USA, 2006.
[115] K. K.-F. Cheng, "Oral mucositis, dysfunction, and distress in patients undergoing cancer therapy," Journal of Clinical Nursing, vol. 16, no. 11, pp. 2114-2121, 2007.

[116] A. Chan and R. J. Ignoffo, "Survey of topical oral solutions for the treatment of chemo-induced oral mucositis," Journal of Oncology Pharmacy Practice, vol. 11, no. 4, pp. 139-143, 2005.

[117] D. M. Keefe, M. M. Schubert, L. S. Elting et al., "Updated clinical practice guidelines for the prevention and treatment of mucositis," Cancer, vol. 109, no. 5, pp. 820-831, 2007.

[118] R. Spielberger, P. Stiff, W. Bensinger et al., "Palifermin for oral mucositis after intensive therapy for hematologic cancers," The New England Journal of Medicine, vol. 351, no. 25, pp. 25902598, 2004.

[119] E. Schmidt, N. H. Thoennissen, A. Rudat et al., "Use of palifermin for the prevention of high-dose methotrexate-induced oral mucositis," Annals of Oncology, vol. 19, no. 9, pp. 1644-1649, 2008.

[120] S. Vadhan-Raj, J. Trent, S. Patel et al., "Single-dose palifermin prevents severe oral mucositis during multicycle chemotherapy in patients with cancer: a randomized trial," Annals of Internal Medicine, vol. 153, no. 6, pp. 358-367, 2010.

[121] R. V. Lalla, S. T. Sonis, and D. E. Peterson, "Management of Oral Mucositis in Patients Who Have Cancer," Dental Clinics of North America, vol. 52, no. 1, pp. 61-77, 2008.

[122] G. B. L. Silva, E. F. Mendonça, C. Bariani, H. S. Antunes, and M. A. G. Silva, "The prevention of induced oral mucositis with low-level laser therapy in bone marrow transplantation patients: a randomized clinical trial," Photomedicine and Laser Surgery, vol. 29, no. 1, pp. 27-31, 2011.

[123] J. E. Noé, "L-glutamine use in the treatment and prevention of mucositis and cachexia: a naturopathic perspective," Integrative Cancer Therapies, vol. 8, no. 4, pp. 409-415, 2009.

[124] D. E. Peterson, J. B. Jones, and R. G. Petit II, "Randomized, placebo-controlled trial of saforis for prevention and treatment of oral mucositis in breast cancer patients receiving anthracycline-based chemotherapy," Cancer, vol. 109, no. 2, pp. 322-331, 2007.

[125] I. Sukhotnik, J. G. Mogilner, R. Karry et al., "Effect of oral glutamine on enterocyte turnover during methotrexate-induced mucositis in rats," Digestion, vol. 79, no. 1, pp. 5-13, 2009.

[126] I. Sukhotnik, J. G. Mogilner, D. Shteinberg et al., "Leptin accelerates enterocyte turnover during methotrexate-induced intestinal mucositis in a rat," Cancer Biology and Therapy, vol. 8, no. 10, pp. 899-906, 2009.

[127] R. Rautemaa, A. Lauhio, M. P. Cullinan, and G. J. Seymour, "Oral infections and systemic disease-an emerging problem in medicine," Clinical Microbiology and Infection, vol. 13, no. 11, pp. 1041-1047, 2007.

[128] R. V. Lalla, M. C. Latortue, C. H. Hong et al., "A systematic review of oral fungal infections in patients receiving cancer therapy," Supportive Care in Cancer, vol. 18, no. 8, pp. 985-992, 2010.

[129] H. V. Worthington, J. E. Clarkson, T. Khalid, S. Meyer, and M. McCabe, "Interventions for treating oral candidiasis for patients with cancer receiving treatment," Cochrane Database of Systematic Reviews), vol. 7, p. CD001972, 2010.

[130] P. G. Pappas, C. A. Kauffman, D. Andes et al., "Clinical practice guidelines for the management of candidiasis: 2009 Update by the Infectious Diseases Society of America," Clinical Infectious Diseases, vol. 48, no. 5, pp. 503-535, 2009.

[131] J. F. G. M. Meis and P. E. Verweij, "Current management of fungal infections,” Drugs, vol. 61, no. 1, pp. 13-25, 2001. 
[132] J. A. Vazquez, "Invasive oesophageal candidiasis: current and developing treatment options," Drugs, vol. 63, no. 10, pp. 971989, 2003.

[133] C. D. Collins, J. J. Ellis, and D. R. Kaul, "Comparative costeffectiveness of posaconazole versus fluconazole or itraconazole prophylaxis in patients with prolonged neutropenia," American Journal of Health-System Pharmacy, vol. 65, no. 23, pp. 22372243, 2008.

[134] W. Schonfeld, J. Wang Cheng, K. B. Tong, and R. Seifeldin, "Cost-effectiveness analysis of antifungal prophylaxis in patients undergoing hematopoietic stem cell transplantation," Clinical Therapeutics, vol. 30, no. 5, pp. 964-973, 2008.

[135] W. B. Stam, A. K. O'Sullivan, B. Rijnders et al., "Economic evaluation of posaconazole vs. standard azole prophylaxis in high risk neutropenic patients in the Netherlands," European Journal of Haematology, vol. 81, no. 6, pp. 467-474, 2008.

[136] H. S. Sohn, T.-J. Lee, J. Kim, and D. Kim, "Cost-effectiveness analysis of micafungin versus fluconazole for prophylaxis of invasive fungal infections in patients undergoing hematopoietic stem cell transplantation in Korea," Clinical Therapeutics, vol. 31, no. 5, pp. 1105-1115, 2009.

[137] R. De La Cámara, I. Jarque, M. A. Sanz et al., "Economic evaluation of posaconazole vs fluconazole in the prevention of invasive fungal infections in patients with GVHD following haematopoietic SCT,' Bone Marrow Transplantation, vol. 45, no. 5, pp. 925-932, 2010.

[138] S. Elad, Y. Zadik, I. Hewson et al., "A systematic review of viral infections associated with oral involvement in cancer patients: a spotlight on Herpesviridea," Supportive Care in Cancer, vol. 18, no. 8, pp. 993-1006, 2010.

[139] A.-M. Glenny, L. M. Fernandez Mauleffinch, S. Pavitt, and T. Walsh, "Interventions for the prevention and treatment of herpes simplex virus in patients being treated for cancer," Cochrane Database of Systematic Reviews, no. 1, Article ID CD006706, 2009.

[140] P. Reusser, "Management of viral infections in immunocompromised cancer patients," Swiss Medical Weekly, vol. 132, no. 27-28, pp. 374-378, 2002.

[141] P. G. Arduino and S. R. Porter, "Oral and perioral herpes simplex virus type 1 (HSV-1) infection: review of its management," Oral Diseases, vol. 12, no. 3, pp. 254-270, 2006.

[142] S. Chilukuri and T. Rosen, "Management of acyclovir-resistant herpes simplex virus," Dermatologic Clinics, vol. 21, no. 2, pp. 311-320, 2003.

[143] S. Syrjanen, P. Laine, M. Niemela, and R.-P. Happonen, "Oral hairy leukoplakia is not a specific sign of HIV-infection but related to immunosuppression in general," Journal of Oral Pathology and Medicine, vol. 18, no. 1, pp. 28-31, 1989.

[144] H.-H. Cho, S.-H. Kim, S.-H. Seo et al., "Oral hairy leukoplakia which occurred as a presenting sign of acute myeloid leukemia in a child," Annals of Dermatology, vol. 22, no. 1, pp. 73-76, 2010.

[145] J. Blomgren and H. Bäck, "Oral hairy leukoplakia in a patient with multiple myeloma," Oral Surgery, Oral Medicine, Oral Pathology, Oral Radiology, and Endodontics, vol. 82, no. 4, pp. 408-410, 1996.

[146] O. Nicolatou, G. Nikolatos, M. Fisfis et al., "Oral hairy leukoplakia in a patient with acute lymphocytic leukemia," Oral Diseases, vol. 5, no. 1, pp. 76-79, 1999.

[147] E. Piperi, J. Omlie, I. G. Koutlas, and S. Pambuccian, "Oral hairy leukoplakia in HIV-negative patients: report of 10 cases," International Journal of Surgical Pathology, vol. 18, no. 3, pp. 177-183, 2010 .
[148] D. M. Walling, C. M. Flaitz, and C. M. Nichols, "Epstein-Barr virus replication in oral hairy leukoplakia: response, persistence, and resistance to treatment with valacyclovir," Journal of Infectious Diseases, vol. 188, no. 6, pp. 883-890, 2003.

[149] M. D. G. Moura, T. R. M. Guimarães, L. M. S. Fonseca, I. de Almeida Pordeus, and R. A. Mesquita, "A random clinical trial study to assess the efficiency of topical applications of podophyllin resin (25\%) versus podophyllin resin $(25 \%)$ together with acyclovir cream (5\%) in the treatment of oral hairy leukoplakia," Oral Surgery, Oral Medicine, Oral Pathology, Oral Radiology, and Endodontics, vol. 103, no. 1, pp. 64-71, 2007.

[150] M. D. G. Moura, J. P. A. Haddad, M. I. B. Senna, E. Ferreira E Ferreira, and R. A. Mesquita, "A new topical treatment protocol for oral hairy leukoplakia," Oral Surgery, Oral Medicine, Oral Pathology, Oral Radiology and Endodontology, vol. 110, no. 5, pp. 611-617, 2010.

[151] S. S. Bhandarkar, J. MacKelfresh, L. Fried, and J. L. Arbiser, "Targeted therapy of oral hairy leukoplakia with gentian violet," Journal of the American Academy of Dermatology, vol. 58, no. 4, pp. 711-712, 2008.

[152] B. J. Cowart, "Taste dysfunction: a practical guide for oral medicine," Oral Diseases, vol. 17, no. 1, pp. 2-6, 2011.

[153] A. J. Hovan, P. M. Williams, P. Stevenson-Moore et al., "A systematic review of dysgeusia induced by cancer therapies," Supportive Care in Cancer, vol. 18, no. 8, pp. 1081-1087, 2010.

[154] M. Y. Halyard, "Taste and smell alterations in cancer patientsreal problems with few solutions," Journal of Supportive Oncology, vol. 7, no. 2, pp. 68-69, 2009.

[155] M. Fink, "Vitamin D deficiency is a cofactor of chemotherapyinduced mucocutaneous toxicity and dysgeusia," Journal of Clinical Oncology, vol. 29, no. 4, pp. e81-e82, 2011.

[156] P. Ravasco, I. Monteiro-Grillo, P. M. Vidal, and M. E. Camilo, "Impact of nutrition on outcome: a prospective randomized controlled trial in patients with head and neck cancer undergoing radiotherapy," Head and Neck, vol. 27, no. 8, pp. 659-668, 2005.

[157] P. Ravasco, I. Monteiro-Grillo, P. M. Vidal, and M. E. Camilo, "Dietary counseling improves patient outcomes: a prospective, randomized, controlled trial in colorectal cancer patients undergoing radiotherapy," Journal of Clinical Oncology, vol. 23, no. 7, pp. 1431-1438, 2005. 


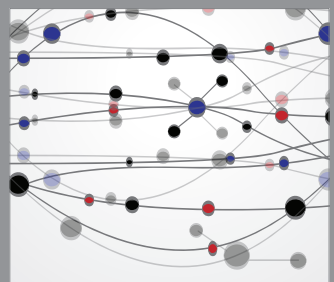

The Scientific World Journal
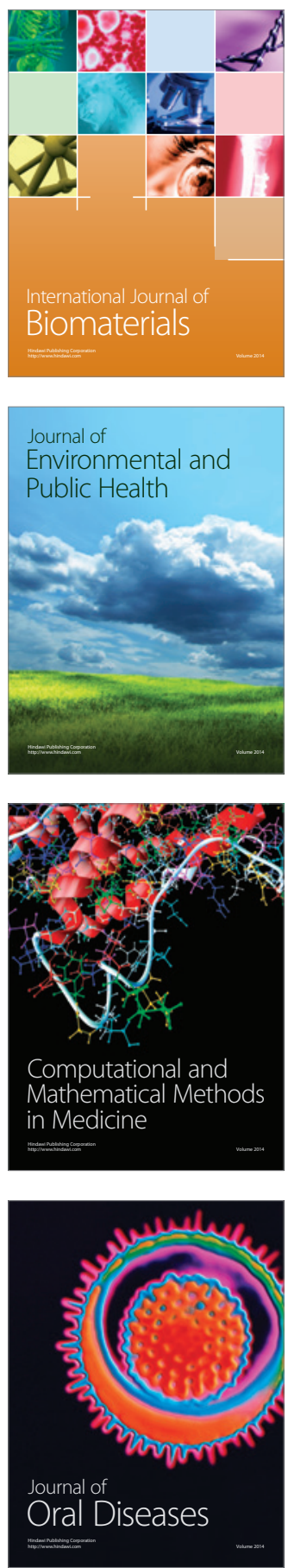
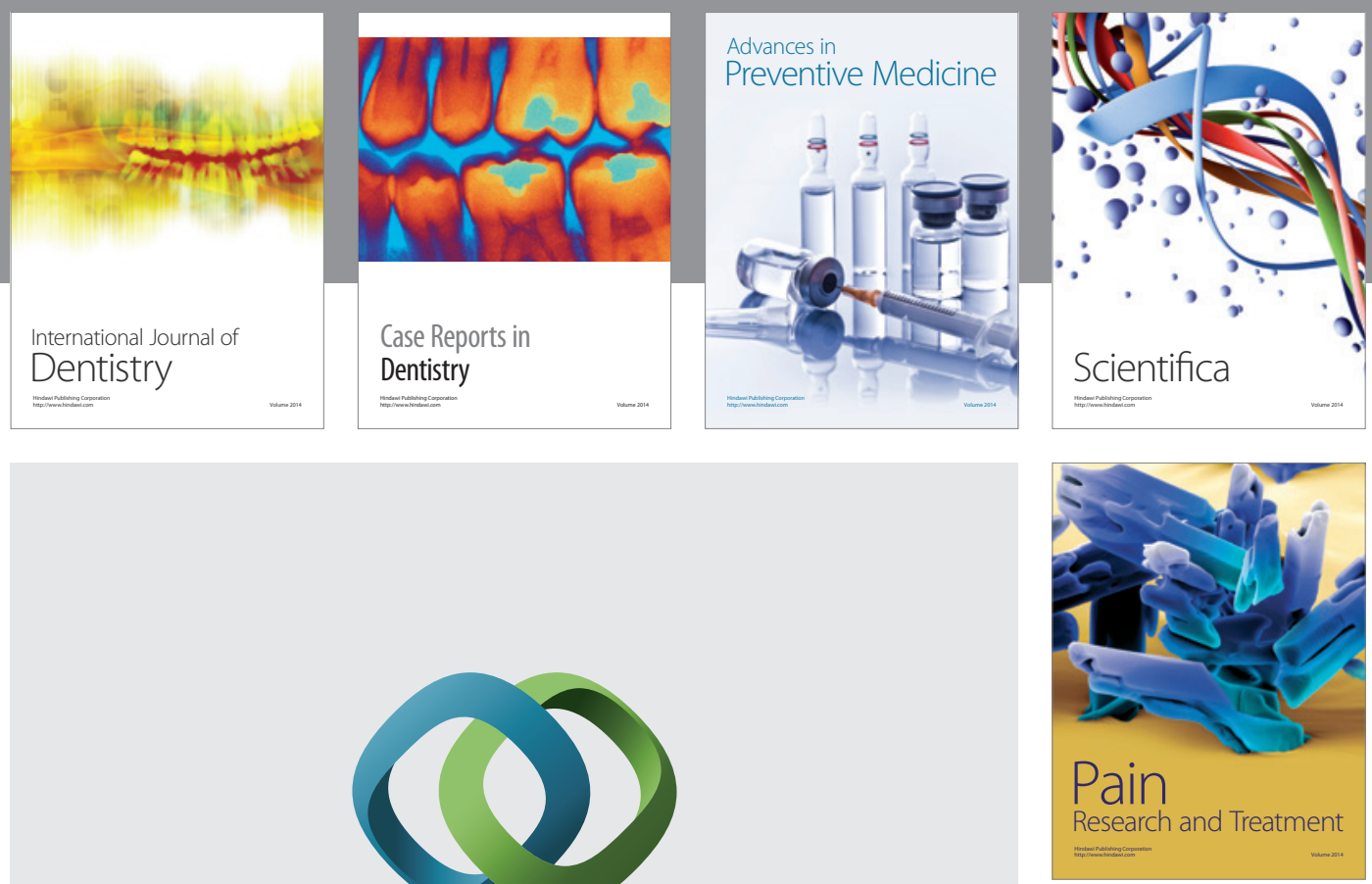

\section{Hindawi}

Submit your manuscripts at

http://www.hindawi.com
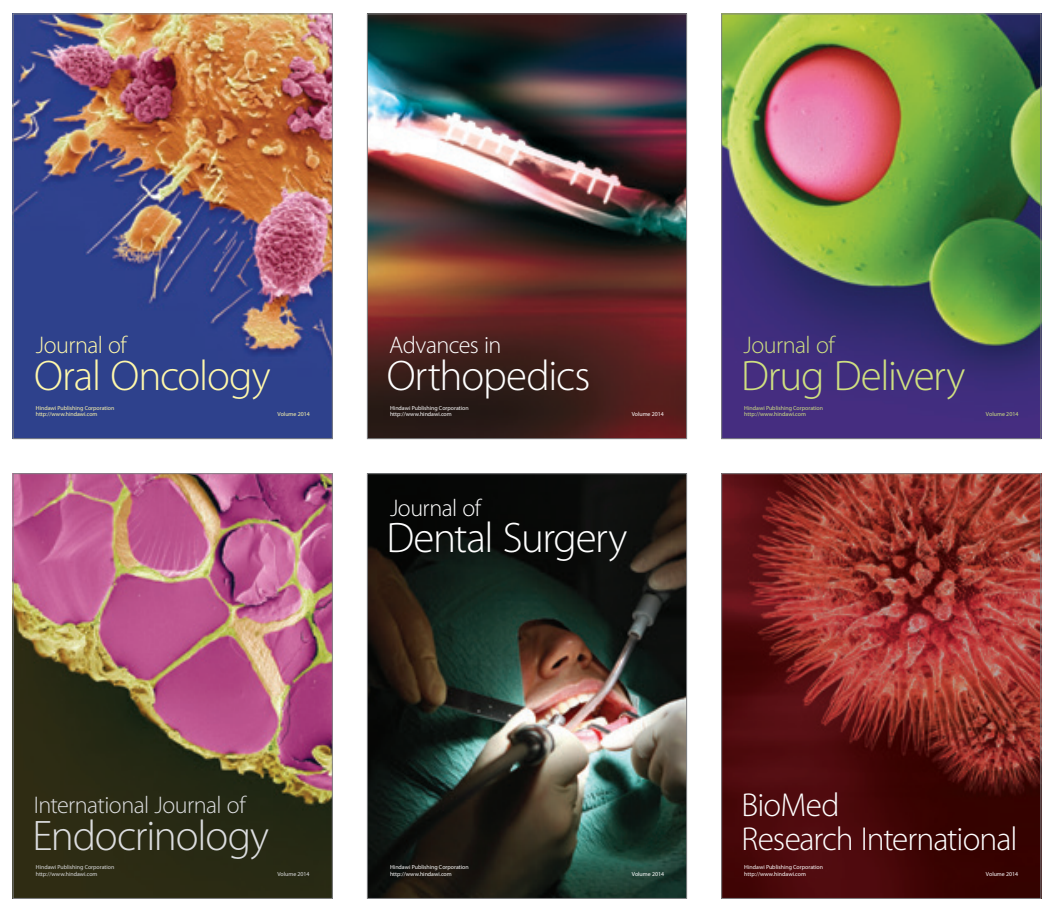

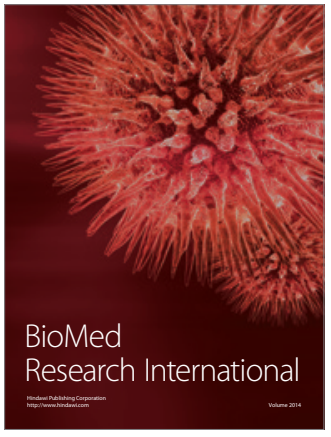

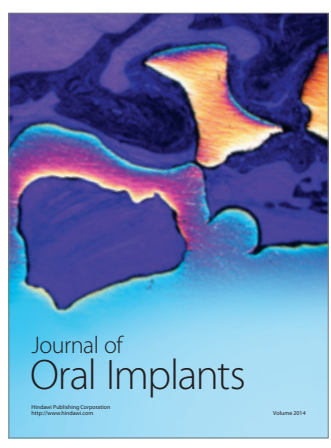
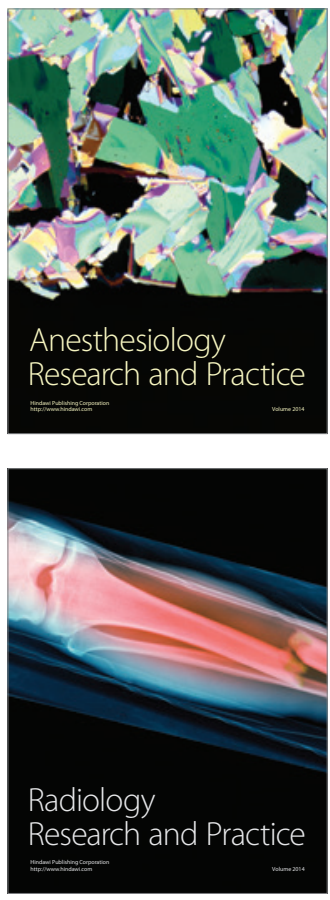